\title{
One-Pot Process of Anthraquinone Synthesis in the Presence of Mo-V-P Heteropoly Acid Solutions as a Bifunctional Catalysts
}

\author{
Leonid Gogin*, Elena Zhizhina \\ Boreskov Institute of Catalysis, Novosibirsk, Russia \\ Email: "gogin@catalysis.ru
}

Received January 24, 2013; revised March 13, 2013; accepted April 11, 2013

Copyright (C) 2013 Leonid Gogin, Elena Zhizhina. This is an open access article distributed under the Creative Commons Attribution License, which permits unrestricted use, distribution, and reproduction in any medium, provided the original work is properly cited.

\begin{abstract}
Acid-catalytic 1,3-butadiene condensation with para-quinones followed by the obtained product oxidation may be performed in one stage as one-pot process, if assisted by the aqueous solutions of Mo-V-P heteropoly acids with a composition of $\mathrm{H}_{\mathrm{a}} \mathrm{P}_{\mathrm{z}} \mathrm{Mo}_{\mathrm{y}} \mathrm{V}_{\mathrm{x}} \mathrm{O}_{\mathrm{b}}$. 1,4-naphthoquinone condensation with 1,3-butadiene in the HPA solutions with no organic solvents yields 9,10-anthraquinone (AQ) mixed with tetrahydro-AQ (THA) and dihydro-AQ (DHA). However, AQ yield and its purity may be considerably improved by using water-mixable organic solvents, e.g., acetone, 1,4-dioxane, as well as high vanadium content $\mathrm{HPA}$ such as $\mathrm{H}_{15} \mathrm{P}_{4} \mathrm{Mo}_{18} \mathrm{~V}_{7} \mathrm{O}_{89}$ and $\mathrm{H}_{17} \mathrm{P}_{3} \mathrm{Mo}_{16} \mathrm{~V}_{10} \mathrm{O}_{89}$. Process optimization provides $70 \%$ yield of reaction product containing no less than $90 \% \mathrm{AQ}$.
\end{abstract}

Keywords: 9,10-Anthraquinone; Mo-V-P Heteropoly Acids; Diene Synthesis; Organic Solvents

\section{Introduction}

9,10-Anthraquinone (AQ) is a quite important product of organic synthesis [1]. Diene synthesis is known as one of industrial processes for producing AQ. This method bases on the 1,4-naphthoquinone (NQ) reaction with 1,3-butadiene [1]. Primary addition products (adducts) are obtained in organic solvents under 1,3-butadiene pressure rising to $0.3-2 \mathrm{MPa}$ or in the presence of organic acids allowing to reduce the pressure. Prepared 1,4,4a9atetrahydroAQ (THA) is then oxidized into $\mathrm{AQ}$ by strong oxidizers (e.g., $\mathrm{CuCl}_{2}, \mathrm{H}_{2} \mathrm{O}_{2}$ or $\mathrm{NaClO}_{3}$ [2]) in the acid medium or by air oxygen in the alkaline medium [3].

Earlier [4,5] we suggested to use the aqueous solutions of Mo-V-P heteropoly acids (HPA), which are simultaneously acid catalysts and oxidizers, to produce AQ via 1,4-naphthoquinone reaction with 1,3-butadiene. Using of HPA solutions as bifunctional catalysts allows to carry out the AQ synthesis as a one-pot process (See Scheme 1). At process completion the reduced HPA solution may be filtered away from the solid product and afterwards regenerated, e.g., by oxygen under pressure [6].

In the previous studies $[4,5]$ butadiene reaction with NQ in the HPA solution is shown to yield the product mixtures containing AQ and its partially hydrogenated derivatives THA and 1,4-dihydroAQ (DHA). With this regard, in the present work we tried to optimize the onepot process to obtain practically pure AQ. We have specified conditions, allowing almost complete shift of the adduct oxidation towards the $\mathrm{AQ}$ synthesis.

\section{Experimental}

In all studies we used 1,4-naphthoquinone Alfa Aesar,

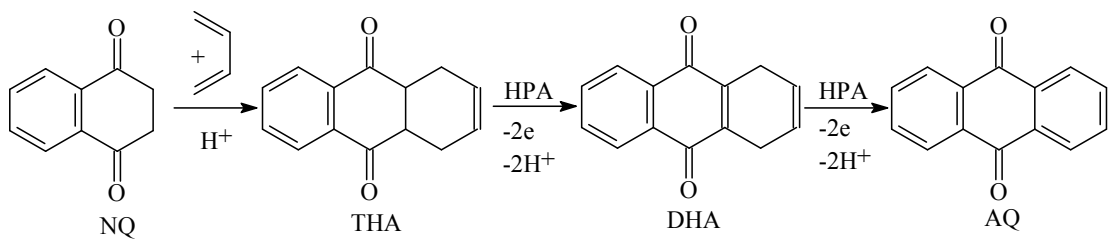

Scheme 1. One-pot process of anthraquinone preparation by diene synthesis in Mo-V-P heteropoly acid solutions.

"Corresponding author. 
1,3-butadiene $\left(\mathrm{C}_{4} \mathrm{H}_{6}\right)$ of $99 \%$ purity. HPA-x ( $\mathrm{x}$ - the number of $\mathrm{V}$ atoms) solutions of different brutto-compositions: Keggin solution of $\mathrm{H}_{7} \mathrm{PMo}_{8} \mathrm{~V}_{4} \mathrm{O}_{40}$ (HPA-4) and the high vanadium content non-Keggin solutions

$\mathrm{H}_{15} \mathrm{P}_{4} \mathrm{Mo}_{18} \mathrm{~V}_{7} \mathrm{O}_{89}$ and $\mathrm{H}_{17} \mathrm{P}_{3} \mathrm{Mo}_{16} \mathrm{~V}_{10} \mathrm{O}_{89}$ (HPA-7 and HPA-10, respectively) were prepared according to method described in [7].

HPLC method was applied for reaction product analysis. For the purpose we used liquid chromatograph ProStar equipped with UV-detector (wavelength $247 \mathrm{~nm}$ ). Separation was done on column Pursuit 3 C18, $247 \times 4.6$ $\mathrm{mm}$, eluting reagent flow rate being $1 \mathrm{ml} / \mathrm{min}$. We used commercial available solvents for the chromatography without further purification. Eluting composition was $70 \% \mathrm{CH}_{3} \mathrm{OH}+30 \% \mathrm{CF}_{3} \mathrm{COOH}$, sample solvent $\mathrm{CHCl}_{3}$.

$\mathrm{AQ}$ synthesis was performed in a thermostat autoclave of stainless steel with inserted glass beaker. $15.6 \mathrm{ml}$ of $0.2 \mathrm{M}$ HPA solution and $0.2 \mathrm{~g}$ of substrate (NQ) were put into the beaker. If necessary, preliminary NQ was dissolved in the organic solvent. Then autoclave was connected to a butadiene vessel and blown with butadiene to remove air (at required temperature without stirring).

After that autoclave was linked to preliminary heated thermostat, and stirring was put on. All AQ processes were performed under intensive mixing with magnetic stirring $\left(650 \mathrm{~min}^{-1}\right)$ for $1-9$ hours in the butadiene atmosphere.

Precipitated solid products were filtered, washed with water and dried over $\mathrm{P}_{2} \mathrm{O}_{5}$ in vacuum. Additional (less $10 \%$ ) quantity of product was extracted from the filtrate by chloroform $(3 \times 30 \mathrm{ml})$. Thus obtained extract after drying over $\mathrm{MgSO}_{4}$ was evaporated to the dry powder. The combined dry product was weighed, and then exposed to the HPLC analysis. Further in tables it is given the content of combined product.

The NQ conversion was calculated according to formula:

$$
\mathrm{X}_{\mathrm{NQ}}=\left(\mathrm{M} \times \mathrm{C}_{\mathrm{NQ}} \times 100\right) / \mathrm{M}_{\mathrm{NQ}},
$$

where $\mathrm{M}$ is the dry product mass, $\mathrm{g} ; \mathrm{C}_{\mathrm{NQ}}$ is the NQ por- tion in precipitate according to analysis; $\mathrm{M}_{\mathrm{NQ}}$ - the starting NQ mass, $\mathrm{g}$.

The AQ yield was calculated according to the formula:

$$
\mathrm{Y}_{\mathrm{AQ}}=\left(\mathrm{M} \times \mathrm{C}_{\mathrm{AQ}} \times 100\right) / 0.263,
$$

where $\mathrm{M}$ is the dry product mass, $\mathrm{g}$; $\mathrm{C}_{\mathrm{AQ}}$ is the $\mathrm{AQ}$ portion in precipitate according to analysis; 0.263 - the theoretically possible value of AQ mass (for full NQ conversion into $\mathrm{AQ}), \mathrm{g}$.

\section{Results and Discussion}

As we have already mentioned [4,5], when we performed the one-pot process under $\mathrm{P}=0.1 \mathrm{MPa}$ and at $\mathrm{T}=80^{\circ} \mathrm{C}$ $90^{\circ} \mathrm{C}$ without organic solvents or in the presence of solvents poorly mixing with water, we obtained the mixtures of 4 products (traces NQ + THA + DHA + AQ), AQ content never being higher than $50 \%$. To solve problem of maximizing the AQ yield and purity in the onepot synthesis, we tried to optimize its conditions.

The attempt to increase reaction temperature to $135^{\circ} \mathrm{C}$ failed to provide essentially higher AQ content. Therefore, our studies were continued at temperatures below $100^{\circ} \mathrm{C}$

We have assumed reaction mixture heterogeneity to be responsible for the incomplete oxidation of the diene synthesis adducts in the presence of the aqueous HPA solutions. Indeed, NQ is poorly soluble in the HPA solution, while THA and DHA do not solve even on heating. Moreover, the earlier used non polar organic solvents did not mix well with the HPA solutions. Therefore, some organic solvent easily dissolving NQ and easily mixing with water might help the process optimization towards the higher AQ yield. Additional demand to such a solvent was its good resistance to HPA, the latter being a rather strong oxidizer.

In Table 1 one may see the results of experiments with several hydrophilic solvents. Apparently, acetone and 1,4-dioxane provide the product containing mainly $\mathrm{AQ}$ and DHA, THA and NQ contents being rather low. Dimethylsulfoxide (DMSO) and especially isopropanol

Table 1. Dependence of the AQ synthesis parameters on the organic solvent nature. Reaction conditions: $15.6 \mathrm{ml} 0.2 \mathrm{M}$ water

\begin{tabular}{|c|c|c|c|c|c|c|c|}
\hline \multirow{2}{*}{ Solvent, ml } & \multirow{2}{*}{$\mathrm{T}\left({ }^{\circ} \mathrm{C}\right)$} & \multicolumn{4}{|c|}{ Reaction products (mol \%) } & \multirow{2}{*}{$\mathrm{X}_{\mathrm{NQ}}(\%)$} & \multirow{2}{*}{ Yield of AQ (\%) } \\
\hline & & AQ & THA & DHA & NQ & & \\
\hline Water $^{*}$ & 80 & 51.7 & 22.9 & 16 & 4.1 & 97.1 & 27.9 \\
\hline Acetone (8) & 60 & 83.4 & 1.8 & 12.6 & 0.4 & 99.5 & 73.4 \\
\hline Isopropanol (8) & 80 & 58 & 16.5 & 17 & 3.4 & 97.3 & 35.7 \\
\hline DMSO (8) & 80 & 72.3 & 9.9 & 13.3 & 0.8 & 99.7 & 22.8 \\
\hline 1,4-dioxane (8) & 80 & 84.5 & - & 14.7 & 0.2 & 99.8 & 69.7 \\
\hline
\end{tabular}
solution of HPA-4, molar ratio $\mathrm{HPA}-4 / \mathrm{NQ}=2$, butadiene pressure $\mathrm{P}=200 \mathrm{kPa}-\mathrm{P}_{\mathrm{H}_{2} \mathrm{O}}$, reaction time $7 \mathrm{~h}$.

*Reaction time: $9 \mathrm{~h}$. 
Table 2. AQ synthesis parameters versus the HPA composition. Reaction conditions: $15.6 \mathrm{ml} 0.2 \mathrm{M}$ water solution of HPA-x, molar ratio $\mathrm{HPA}-\mathrm{x} / \mathrm{NQ}=2$, butadiene pressure $\mathrm{P}=200 \mathrm{kPa}-\mathbf{P}_{\mathrm{H}_{2} \mathrm{O}}$, organic solvent volume $-8 \mathrm{ml}$.

\begin{tabular}{ccccccc}
\hline HPA-x & Solvent & Time $(\mathrm{h})$ & $\mathrm{T}\left({ }^{\circ} \mathrm{C}\right)$ & AQ content in product $(\%)$ & $\mathrm{X}_{\mathrm{NQ}}(\%)$ & AQ yield $(\%)$ \\
\hline HPA-4 & Water & 9 & 80 & $51.7^{*}$ & 97.1 & 27.9 \\
HPA-4 & Acetone & 7 & 60 & $83.4^{*}$ & 99.5 & 73.4 \\
HPA-7 & Acetone & 7 & 60 & $91.6^{* *}$ & 99.6 & 65.0 \\
HPA-4 & 1,4-dioxane & 7 & 80 & $84.5^{*}$ & 99.8 & 69.7 \\
HPA-7 & 1,4-dioxane & 7 & 80 & $91.3^{* *}$ & 99.7 & 69.3 \\
HPA-10 & 1,4-dioxane & 7 & 80 & $94.9^{* *}$ & 99.7 & 69.0 \\
HPA-10 & 1,4-dioxane & 7 & 90 & $96.9^{* *}$ & 99.7 & 69.0 \\
\hline
\end{tabular}

*Product also contains THA and DHA; ${ }^{* *}$ Product contains only DHA beside AQ.

considerably worsened the final result. The reason most likely lies in the incomplete substrate dissolving in isopropanol. Since there is still some amount of DHA in the product in the presence of above mentioned solvents, we have also tried the HPA-x solutions with high vanadium content (HPA-7 and HPA-10) instead of the HPA-4 solution.

Experimental results are shown in Table 2. As HPA-7 was added to acetone in the course of one-pot process, reaction product contained $91.6 \% \mathrm{AQ}$ and $8.4 \%$ DHA. HPA-10 with dioxane provided 97\% AQ (balance DHA), reaction temperature and duration being $90^{\circ} \mathrm{C}$ and $7 \mathrm{~h}$, respectively. In this case NQ conversion was $99.7 \%$, and AQ yield was $67 \%$.

Side oxidation processes in the presence of high vanadium content HPA-7 and HPA-10 can account for small total AQ yield decrease in comparison with HPA-4.

Therefore, the simultaneous use of water mixable organic solvent and sufficiently strong oxidizer (HPA-10 solution) allows to obtain AQ having purity up to $97 \%$.

Before catalyst is recovered via reaction (2) by oxygen [8] solvents are distilled from reaction mixture. Thus all solvents are recycled in the following one-pot processes.

\section{Conclusions}

Therefore, we have optimized the one-pot synthesis conditions to obtain 9,10-anthraquinone via 1,4-naphthoquinone reaction with 1,3 -butadiene in the presence of the aqueous solutions of Mo-V-P heteropoly acids. The latter acts as bifunctional catalysts, i.e. acid catalysts in the diene synthesis and redox catalysts, oxidizing the diene synthesis adducts.

It has been shown that it is necessary to use polar water mixable organic solvents (acetone, 1,4-dioxane, etc.) to provide the desired (more than 90\%) AQ content in the product and as high as possible the AQ yield (around
$70 \%$ ). The best results were obtained using these organic solvents and Mo-V-P HPA-10 with a high content of vanadium, its brutto composition being $\mathrm{H}_{17} \mathrm{P}_{3} \mathrm{Mo}_{16} \mathrm{~V}_{10} \mathrm{O}_{89}$.

\section{REFERENCES}

[1] M. V. Gorelik, "Chemistry of Anthraquinones and Their Derivatives," Khimia, Moscow, 1983.

[2] H. S. Ju, Y. J. Ju, J. E. Kim and J. I. Won, "Preparation of Napthoquinone and Anthraquinone Using Oxidizing Agent," KR Patent No. 2001004856, 2001.

[3] H. S. Ju, Y. J. Ju, J. E. Kim and J. I. Won, "Method of Manufacturing Anthraquinone from 1,4-Napthoquinone and 1,3-Butadiene," KR Patent No. 2000001821, 2000.

[4] E. G. Zhizhina, K. I. Matveev and V. V. Russkikh, "1,4Naphto- and 9,10-Anthraquinone Catalytic Preparation by Diene Synthesis Reaction for Cellulose-Paper Industry," Khimiya v Interesakh Ustoichivogo Razvitiya, Vol. 12, 2004, pp. 47-51.

[5] E. G. Zhizhina and V. F. Odyakov, "Aqueous Solutions of Mo-V-P Heteropoly Acids as Bifunctional Catalysts for Preparation of 9,10-Anthraquinone and Its Hydrogenated Derivatives," ChemCatChem, Vol. 4, No. 9, 2012, pp. 1405-1410. doi:10.1002/cctc.201200039

[6] E. G. Zhizhina, M. V. Simonova, V. F. Odyakov and K. I. Matveev, "Regeneration of Catalysts Based on Aqueous Solutions of Mo-V-P Heteropoly Acids," Khimiya v Interesakh Ustoichivogo Razvitiya, Vol. 6, 2004, pp. 683688.

[7] V. F. Odyakov and E. G. Zhizhina, "New Method for Synthesis of Water Solutions of Mo-V-P Heteropoly Acids," Russian Journal of Inorganic Chemistry, Vol. 54, No. 3, 2009, pp. 409-414. doi:10.1134/S003602360903005X

[8] E. G. Zhizhina and V. F. Odyakov, "Physicochemical Properties of Catalysts Based on Aqueous Solutions of Mo-V-phosphoric Heteropoly Acids," Applied Catalysis A: General, Vol. 358, No. 2, 2009, pp. 254-258. doi:10.1016/j.apcata.2009.02.021 